Interactive comment on "Vertical distribution of atmospheric particulate matters within urban boundary layer in southern China:

size-segregated chemical composition and secondary formation through cloud processing and heterogeneous reactions" by Shengzhen

\title{
Zhou et al.
}

Barbara Ervens (Editor)

barbara.ervens@uca.fr

Received and published: 20 April 2020

The review process of this manuscript was unusually long and involved comments of two referees during the discussion period and two more during the following revisions of the manuscript. All referees generally agreed that vertically-resolved aerosol mea- 
surements on high towers are quite rare and may provide unique insights to sources and formation processes. However, the underlying processes, namely the formation of particulate sulfate, nitrate and ammonia, have been subject of many previous studies. Though the discussed data set is new, it is not sufficiently developed to substantially advance our understanding of these processes. Despite the major extension of the manuscript to include some model studies during the last phase of the review process, the advances and general implications for the scientific understanding of atmospheric chemistry and physics from this study are too limited to fulfill the standards for a research article in ACP. However, as it reports substantial new measurement results but with limited implications for atmospheric chemistry and physics, I decided to accept it for publication as a "Measurement Report" as it seems well suited for this manuscript category.

Interactive comment on Atmos. Chem. Phys. Discuss., https://doi.org/10.5194/acp-2019-155, 2019. 